\title{
Associations between Adolescents' Interpersonal Relationships, School Well-being, and Academic Achievement during Educational Transitions
}

\author{
Noona Kiuru (ib ${ }^{1} \cdot$ Ming-Te Wang $^{2} \cdot$ Katariina Salmela-Aro $^{3} \cdot$ Lasse Kannas $^{4} \cdot$ Timo Ahonen $^{1} \cdot$ Riikka Hirvonen $^{5}$
}

Received: 11 October 2019 / Accepted: 10 December 2019 / Published online: 31 December 2019

(c) The Author(s) 2020

\begin{abstract}
A youth's ability to adapt during educational transitions has long-term, positive impacts on their academic achievement and mental health. Although supportive relationships with parents, peers, and teachers are protective factors associated with successful educational transitions, little is known about the reciprocal link between the quality of these interpersonal relationships and school well-being, with even less known about how these two constructs affect academic achievement. This longitudinal study examined how the quality of interpersonal relationships and school well-being worked together to affect academic achievement during the transition from primary school to lower secondary school. Data were collected from 848 Finnish adolescents (54\% girls, mean age at the outset 12.3 years) over the course of sixth and seventh grade. The results support a transactional model illustrating the reciprocal associations between the quality of interpersonal relationships and school well-being during the transition to lower secondary school. As such, the presence of high quality interpersonal relationships promoted higher academic achievement through increased school well-being, whereas high school well-being promoted higher subsequent academic achievement through increased quality of interpersonal relationships. Overall, the results suggest that promoting learning outcomes and helping adolescents with challenges during educational transitions is a critical part of supporting school well-being and the formation of high-quality interpersonal relationships.
\end{abstract}

Keywords Early adolescence $\cdot$ School well-being $\cdot$ Interpersonal relationships $\cdot$ Academic achievement $\cdot$ Educational transition

\section{Introduction}

Educational transitions from primary to lower secondary school pose potential risks for declining learning motivation and academic achievement (Eccles 2004). Understanding

Noona Kiuru

noona.h.kiuru@jyu.fi

1 Department of Psychology, University of Jyvaskyla, P.O. Box 35, 40014 Jyväskylä, Finland

2 University of Pittsburg, Pittsburgh, PA, USA

3 Department of Educational Science, University of Helsinki, Helsinki, Finland

4 Faculty of Sport and Health Sciences, University of Jyväskylä, Jyväskylä, Finland

5 School of Applied Educational Science and Teacher Education, University of Eastern Finland, Joensuu, Finland the mechanisms that protect adolescents from disengagement during critical educational transitions is important, because successful adaptation to the new educational context predicts the completion of higher education, better job prospects, and higher life satisfaction (for a review see Upadyaya and Salmela-Aro 2013). The stage-environment fit model suggests that a poor fit between changes in individual (e.g., an intensified need for autonomy; a heightened need for social acceptance and support when facing changes related to puberty) and contextual (e.g., stricter grading practices and increasingly distant relationships with teachers) levels may hinder adolescents' adaptation during educational transitions (Eccles 2004; Hill and Wang 2015). Supportive relationships with parents, school friends, and teachers constitute one possible protective factor that may facilitate successful educational transitions (e.g., Burchinal et al. 2008; Waters et al. 2014) because these positive relationships can promote students' feelings of relatedness and facilitate adaptation to a new school environment (Ryan 
and Deci 2017). Although some theoretical suggestions have been posited on how interpersonal relationships, school well-being, and academic achievement may be related (Sameroff 2009), little is known about the reciprocal dynamics between the quality of interpersonal relationships and school well-being, and how these dynamics contribute to academic achievement. A better understanding of how quality of interpersonal relationships and school well-being work together to affect academic achievement during educational transitions is crucial, since successful adaptation during the critical transitions has long-term impacts on youth's academic and mental-health outcomes (Upaydyaya and Salmela-Aro 2013). Consequently, this study examined (a) the longitudinal associations between quality of interpersonal relationships and school well-being, and (b) the mediating mechanisms through which quality of interpersonal relationships and school well-being combine to predict students' subsequent academic achievement during the transition to lower secondary school.

\section{Adolescent School Well-being and Interpersonal Relationships}

School is a central developmental context in early adolescents' lives. In fact, school can be seen as adolescents' main workplace, characterized by similar features to those of adults, such as standard tasks and activities, deadlines, work responsibility, and feedback routines (Samdal 2017). Similar to the adult workplace, adolescents contend with experiences that cause anxiety or stress, hence affecting their well-being. School well-being plays a significant role not only in current and future well-being and health conditions (Bond et al. 2007; Samdal et al. 2004) but also in subsequent educational outcomes (Upadyaya and SalmelaAro 2013). In this study, adolescent school well-being is defined as school satisfaction and stress that are thought to reflect key aspects of adolescents' emotional experiences of the school environment. School satisfaction describes the overall positivity of adolescents' school experiences and refers to the liking, enjoyment, and interest associated with school (Eccles 2004; Huebner and Gilman 2006); school stress is defined as students' experiences of school-related expectations and demands that exceed their inner resources and endanger their well-being (Salmela-Aro and Upadyaya 2014; Sonmark and Modin 2017).

School well-being is inextricably linked to the school's social context (Sameroff 2009). The most prominent interpersonal relationships during the adolescent years involve friends and teachers at school and parents at home (Eccles and Roeser 2011; Moore et al. 2018; Wentzel 1998). Interpersonal support may be paramount during the transition from primary school to lower secondary school, not least because this change coincides with multiple challenges and changes in the organization and social structure of the educational setting (Eccles 2004). Although adolescents start to establish independence from parents while concurrently investing more time and energy into peer relationships (Steinberg and Morris 2001), parents still serve as important role models, as adolescents build their identities and adjust to new roles and responsibilities (Castro et al. 2015). While peer and teacher relationships are subject to change during this transitional period, parental support tends to remain stable (see also Hill and Wang 2015). Nevertheless, school friends and teachers form primary sources of social support in the school context. Teachers can be seen as temporary attachment figures serving as a safe haven and a secure basis for students (Verschueren 2015). However, particularly peers make students' time at school enjoyable (Kindermann 2016) and adolescence is a developmental period characterized by the heightened desire to "fit in" with peers (Hamm and Zhang 2010).

School-based relationships with teachers and peers have been shown to influence school well-being, and this influence is stronger than that exacted by more distal macrolevel factors, such as income and social-background related factors (Ottová-Jordan et al. 2015; Park et al. 2012). Adolescents themselves have also identified social interactions within the school community as simultaneously being the most rewarding yet the most challenging part of their school careers (Pyhältö et al. 2010). Despite possible changes in these relationships during transitional periods, maintaining supportive relationships with school friends and teachers may play a pivotal role in adolescent school well-being and successful adaptation to a new educational context (see also Longobardi et al. 2016; West et al. 2010).

Adolescents not only form relationships with teachers and peers, they also enter into a dynamic, reciprocal relationship with their school environment. The transactional model (Sameroff 2009) suggests that adolescent development is a product of the continuous dynamic interactions between adolescents and the experiences provided by their social settings (e.g., parents, friends, teachers). The core of the transactional model lies in the interdependent effects of the adolescent and the environment, which are depicted in the reciprocal associations between the adolescent and others. On the one hand, the extent of perceived social support (e.g., closeness and conflict) from parents, school friends, and teachers may promote or undermine adolescent school well-being (i.e., socialization effects). On the other hand, adolescent school well-being may also elicit reactions from significant others, thereby influencing the quality of interpersonal relationships (see also Kerr and Stattin 2003; Nurmi and Kiuru 2015).

The associations between adolescents' school-based interpersonal relationships and school well-being have been well established in the literature (e.g., Baker et al. 
2003; Quin 2017; Wang and Eccles 2012). However, the extant research is mostly limited to studies that use crosssectional designs or examine only unilateral relationships (i.e., either the effect of interpersonal relationships on school well-being-socialization effects-or the effect of school well-being on interpersonal relationships-evocative effects), thus making it difficult to draw conclusions about the direction of associations. Hence, less is known about the reciprocal associations between adolescent school wellbeing and their perceived quality of interpersonal relationships, particularly during the transition from primary to lower secondary school. Along the same line, only a few studies have simultaneously investigated adolescents' interpersonal relationships with different social agents (i.e., parents, friends, teachers) and the effects of both positive (e.g., closeness) and negative (e.g., conflict) aspects of these relationships. According to the attachment-based relationship model (see Pianta 2001; Verschueren 2015) closeness and conflict are considered key dimensions of relationship quality. Closeness is characterized by high levels of warmth and trustworthiness between adolescents and their significant others, whereas conflict refers to strained and conflictual interactions with a negative tone within the relationship.

\section{Interpersonal Relationships, School Well-being, and Academic Achievement}

Supportive interpersonal relationships function as an important resource for promoting students' academic skill development. According to the self-determination theory (SDT), supportive relationships may fulfill the adolescent's basic psychological need for social relatedness (Deci and Ryan 2000). When this need is met, adolescents feel connected to their teacher and peers, which fosters their motivation to behave in socially appropriate ways and concentrate on learning. Interpersonal support may also reduce stress in demanding situations and increase adolescent's focus on and interest in learning tasks (Kiuru et al. 2014; Wang and Eccles 2012). The transactional dynamics between the quality of interpersonal relationships and school well-being may also impact adolescents' academic performance, though no prior studies have investigated these mechanisms during the critical transition from primary to lower secondary school.

Among the studies targeting different age groups, it has been shown that children's classroom engagement is an important mediator between their feelings of relatedness to peers, parents, and teachers and their academic achievement (Wang et al. 2019). In another study, supportive interpersonal environments with peers, parents, and teachers were shown to promote primary school children's academic achievement through increased task- focused behavior (Kiuru et al. 2014). Similarly, the effects of adolescent perceptions of supportive relationships with peers and teachers and the sense of school belonging have been shown to predict later academic achievement via academic engagement (Zimmer-Gembeck et al. 2006). Although rarely examined, the experiences of school wellbeing might also impact the quality of interpersonal relationships (see also Nurmi and Kiuru 2015), which in turn may have consequences for adolescents' subsequent academic achievement. To the authors' best knowledge, no previous cross-lagged longitudinal studies have investigated whether perceived quality of relationships with parents, friends, and teachers together with school well-being predict adolescents' academic achievement during school transitions. A better understanding of these dynamics could provide researchers, educators, and policy-makers means for preventing negative academic development that tend to co-occur during this critical transition.

\section{Current Study}

To overcome the limitations of previous research, this study aimed to investigate transactional associations between interpersonal relationships, school well-being, and academic achievement during the critical transition from primary to lower secondary school (for schematic figure, see Fig. 1). The first research question was to examine the reciprocal relationship between adolescents' perceived quality (i.e., closeness, conflict) of their relationships with parents, school friends, and teachers, and school well-being (i.e., school satisfaction, school stress). It was expected that (a) high levels of closeness to and low levels of conflict with parents, school friends, and teachers would predict increased school well-being, and that (b) high school well-being would predict increased closeness to and decreased conflict with parents, friends, and teachers. The second research question was to examine the extent to which the quality of relationships with parents, school friends, and teachers predicted adolescents' academic achievement through school well-being. It was hypothesized that high closeness to and low conflict with parents, friends, and teachers would predict improved academic achievement through increased school well-being. The final research question was to examine the extent to which school wellbeing predicted adolescents' academic achievement through the perceived quality of their interpersonal relationships. It was hypothesized that high school wellbeing would predict improved academic achievement through increased closeness to and decreased conflict with parents, school friends, and teachers. 


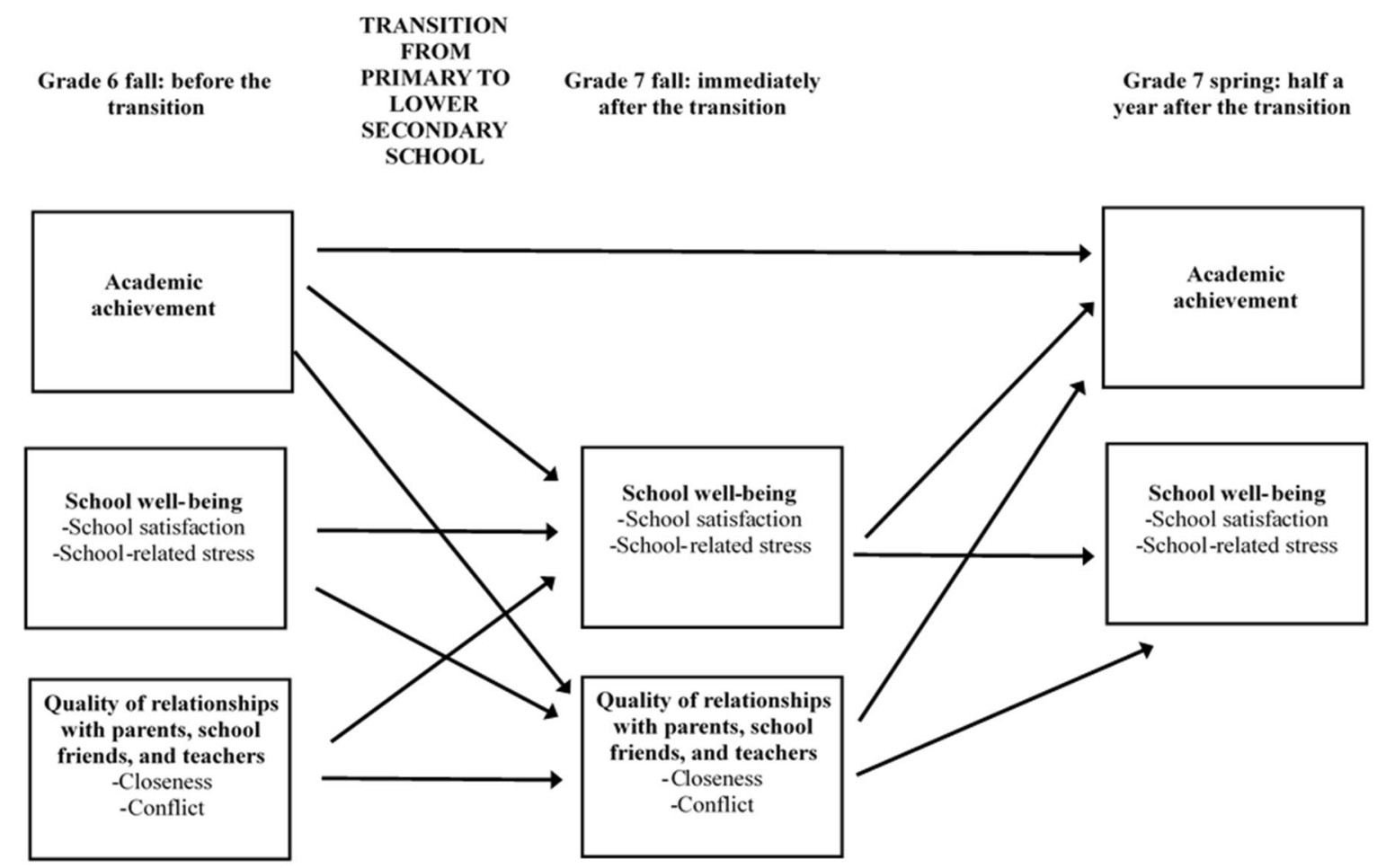

Fig. 1 Schematic model for the role of associations between quality of interpersonal relationships, school well-being, and academic achievement.

\section{Method}

\section{Participants and Procedure}

This study analyzed data from a broader longitudinal study that follows a community sample of Finnish students in Central Finland across the transition from primary to lower secondary school. Finnish children start their education at kindergarten during the year of their sixth birthday. One year later, at age 7 , they move to comprehensive school where they continue for the next 9 years. Comprehensive school divides into a lower level (grades 1-6) and an upper level (grades 7-9). In the Finnish school system, the transition from primary (grades 1-6) to lower secondary school (grades 7-9) marks the first remarkable transition for students. The transition to lower secondary school marks a change in the school environment including multiple changes, such as increased workload, often shifting to other school buildings, and always moving from a classroom teacher system to a subject teacher system with increased amount of new teachers and classmates. For the present study, primary schools were selected from areas where all the children transfer to particular secondary schools instead of dispersing to different locations (see also Mauno et al. 2018).

The sample of this study consisted of 848 adolescents (457 girls, 54\%) who were examined both before (i.e., grade
6) and after (i.e., grade 7) their transition to lower secondary school. These adolescents came from 56 school classes, ranging in size between seven and thirty pupils $(M=21.1, \mathrm{SD}=4.66)$. A total of $91 \%$ of adolescents $(n=$ 770) filled in the questionnaires at all the three time points ( $n=827$ in the fall of the sixth grade; $n=802$ in the fall of the seventh grade; $n=793$ in the spring of the seventh grade); 9\% of adolescents $(n=78)$ completed the questionnaires only once or twice out of three time points.

At the beginning of the study, the participants were in the fall semester of the sixth grade, and their ages ranged from 11 to 13 ( $M=12.3$ years, $\mathrm{SD}=4.36$ months). The participants' mother tongue was Finnish in $98 \%$ of the cases. The sample was fairly representative of the Finnish general population in regard to demographic characteristics (Official Statistics of Finland 2016a, 2016b).

Data were collected during normal school days in the 2014-2016 academic years. Information on adolescent school well-being and perceived quality of interpersonal relationships was collected using questionnaires. All the questionnaires were administered by trained testers with two trained research assistants being present at all the test situations. Information about the participants' academic achievement (i.e., school grades) was obtained from the school registers. The study has been evaluated and approved by the ethics committee of the University of Jyväskylä (February 12, 2014). 


\section{Measures}

\section{School Well-being (Grade 6 Fall; Grade 7 Fall; Grade 7 Spring)}

The adolescents reported their school-related well-being using the items adapted from the Health Behavior in School-aged Children (HBSC) Study (Currie et al. 2012; see also Kämppi et al. 2012). School satisfaction was assessed using three items (e.g., "I enjoy going to school"; $\alpha=0.88-0.90$ ), and school stress was measured using four items (e.g., "I have too much schoolwork"; $\alpha=0.78-0.81$ ) on a 5 -point Likert scale $(1=$ completely disagree; $5=$ completely agree).

\section{Closeness to and Conflict with Parents (Grade 6 Fall; Grade 7 Fall)}

The adolescents were asked to rate their experienced closeness (five items; e.g., "I have a close and warm relationship with my mother/father") and conflict (six items; e.g., "I often argue with my mother/father") with their mothers and fathers using the Child Parent Relationship Scale (CPRS; Driscoll and Pianta 2011; see also Mauno et al. 2018). The adolescents answered the questions on a five-point Likert scale ( $1=$ not true at all; $5=$ completely true). The mean scores were calculated to measure the adolescents' perceived closeness to and conflict with their mothers $(\alpha=0.83-0.86 ; \alpha=0.79-0.86)$ and fathers $(\alpha=$ $0.86-0.87 ; \alpha=0.77-0.86)$, respectively.

\section{Closeness to and Conflict with School Friends (Grade 6 Fall; Grade 7 Fall)}

The adolescents were asked to rate their experiences of closeness (seven items; e.g., "I feel happy when spending time with my friend"; $\alpha=0.86-0.88$ ) and conflict (four items; e.g., "My friend and I argue a lot"; $\alpha=0.75-0.79$ ) with their best friends at school using the Friendship Qualities Scale (Bukowski et al. 1994). The adolescents answered these questions using a five-point Likert scale ( 1 $=$ not true at all $; 5=$ completely true).

\section{Closeness to and Conflict with Teachers (Grade 6 Fall; Grade 7 Fall)}

The adolescents were asked to rate their closeness (five items; e.g., "I have a close and warm relationship with my teacher"; $\alpha=0.80-0.82$ ) and conflict (six items; e.g., "I often argue with my teacher"; $\alpha=0.77-0.84$ ) with their sixth-grade classroom teacher during the 2014 fall semester and with their seventh-grade literacy, math, and other teachers during the 2015 fall semester using the Student-
Teacher Relationship Scale (STRS-Short Form; Pianta 2001; see also Jerome et al. 2008). The adolescents answered the questions on a five-point Likert scale $(1=$ not true at all; $5=$ completely true). The mean scores were calculated across these ratings to attain an estimate of the adolescents' overall perceptions of their closeness to and conflict with their teachers.

\section{Academic Achievement (Grade 6 Fall; Grade 7 Spring)}

Information on the students' grade point average was acquired from the school registers in the fall of the sixth grade and spring of the seventh grade. In Finnish schools, the possible grades range from 4 to 10 , with 5 being the lowest passing grade and 10 the highest passing grade.

\section{Statistical Analyses}

The descriptive statistics were analyzed first (see Table 1). Then the measurement models were estimated by using confirmatory factor analysis separately for each variable, measuring school well-being (i.e., school satisfaction, school stress) and perceived quality of interpersonal relationships (i.e., closeness to and conflict with parents, school friends, and teachers). The measurement models of school well-being consisted of three time points (i.e., Grade 6 fall, Grade 7 fall, and Grade 7 spring), and the measurement models of the quality of interpersonal relationships consisted of two time points (i.e., Grade 6 fall and Grade 7 fall). In these measurement models, factor loadings of the same items were constrained to be equal across time to ensure invariance of the measurement across time, and the latent factors were allowed to correlate with each other. Next, the crosslagged structural equation models for school well-being, perceived quality of interpersonal relationships, and academic achievement were estimated. In these models, factor loadings of the same items were constrained to be equal across time to ensure invariance of the measurement across time. Finally, the direct and indirect effects were estimated with the full cross-lagged structural equation models for school well-being, quality of interpersonal relationships, and academic achievement.

The statistical analyses were performed using the Mplus statistical package (Version 8; Muthén and Muthén 19982018) with the COMPLEX approach to account for the clustered nature of the data (Muthén and Muthén 19982018; see also Asparouhov and Muthén 2006; Muthén and Satorra 1995). For the indirect effects, the coefficient estimates, standard errors, and $\mathrm{p}$ values were reported using the COMPLEX approach. In addition, a bootstrapping procedure was used to confirm the indirect effects and their $95 \%$ confidence intervals (MacKinnon et al. 2004). 
Table 1 Means and standard deviations of the study variables.

\begin{tabular}{lllll}
\hline & $n$ & $M$ & $S D$ & Range of scale \\
\hline School satisfaction (gr6, fall) & 835 & 3.39 & 0.90 & $1-5$ \\
School satisfaction (gr7, fall) & 799 & 3.65 & 0.88 & $1-5$ \\
School satisfaction (gr7, spring) & 781 & 3.34 & 0.94 & $1-5$ \\
School-related stress (gr6, fall) & 835 & 2.50 & 0.81 & $1-5$ \\
School-related stress (gr7, fall) & 799 & 2.46 & 0.84 & $1-5$ \\
School-related stress (gr7, fall) & 781 & 2.77 & 0.86 & $1-5$ \\
Closeness to parents (gr6, fall) & 838 & 3.95 & 0.83 & $1-5$ \\
Closeness to parents (gr7, fall) & 801 & 3.74 & 0.92 & $1-5$ \\
Closeness to friends (gr6, fall) & 833 & 4.13 & 0.72 & $1-5$ \\
Closeness to friends (gr7, fall) & 790 & 4.17 & 0.71 & $1-5$ \\
Closeness to teachers (gr6, fall) & 835 & 2.30 & 0.83 & $1-5$ \\
Closeness to teachers (gr7, fall) & 792 & 2.25 & 0.75 & $1-5$ \\
Conflict with parents (gr6, fall) & 839 & 2.04 & 0.73 & $1-5$ \\
Conflict with parents (gr7, fall) & 801 & 1.88 & 0.78 & $1-5$ \\
Conflict with friends (gr6, fall) & 833 & 1.91 & 0.74 & $1-5$ \\
Conflict with friends (gr7, fall) & 788 & 1.85 & 0.75 & $1-5$ \\
Conflict with teachers (gr6, fall) & 837 & 1.63 & 0.68 & $1-5$ \\
Conflict with teachers (gr7, fall) & 792 & 1.40 & 0.56 & $1-5$ \\
Academic achievement (gr6, fall) & 694 & 8.25 & 0.66 & $5-10$ \\
Academic achievement (gr7, & 768 & 8.14 & 0.89 & $5-10$ \\
spring) & & & & \\
\hline
\end{tabular}

gr6 6th grade, $g r 7$ th grade

The proportion of missing data for the main study variables ranged from $2 \%$ to $18.2 \%(M=5.26 ; \mathrm{SD}=3.91)$. The parameters of the models were estimated using fullinformation maximum likelihood (FIML) with nonnormality robust standard errors (maximum likelihood robust, MLR; Muthén and Muthén 1998-2018). The goodness-of-fit of the estimated models was evaluated using the following absolute goodness-of-fit indices: (a) $\chi^{2}$ test, (b) root mean square error of approximation (RMSEA), (c) standardized root mean square residual (SRMR), and (d) comparative fit index (CFI). The acceptable fit was defined as RMSEA $\leq 0.08$ and $\mathrm{CFI} \geq 0.90$ (Browne and Cudeck 1993; Hoyle 1995; Hu and Bentler 1999).

\section{Results}

\section{Measurement Models}

The measurement models were built using confirmatory factor analysis, enabling to take measurement error into account in the primary analyses. These models were built separately for school satisfaction, school-related stress, and for perceived closeness and conflict in relationships with parents, friends, and teachers. In these models, factor loadings of the same items were constrained to be equal across time to ensure invariance of the measurement across time. If required for model fit, some autocovariances of residuals of the same items were estimated. The measurement models, assuming measurement invariance across time, fit the data well: $\chi^{2}(1-73)=0.67-258.80-59.62, p s=$ $0.00-0.79$, RMSEAs $=0.00-0.06$, CFIs $=0.94-1.00$, and SRMRs $=0.03-0.06$. The standardized estimates of factor loadings for the key constructs were high (i.e., no factor loading was lower than 0.40). The fact that the models fit the data well with high factor loadings suggests good structural validity and item reliability.

\section{Structural Equation Models for Interpersonal Relationships and School Well-being}

The first aim of this research was to investigate the extent to which the adolescents' perceived quality of interpersonal relationships predict their subsequent school well-being and vice versa. Table 2 presents the correlations between the latent factors in Grades 6 and 7 and academic achievement. As the aim was to get a distinct picture of the negative and positive aspects of the perceived interpersonal relationships, the cross-lagged SEM models for school well-being were carried out separately for relationship closeness and conflict variables.

\section{Closeness of Interpersonal Relationships and School Well-being}

The final model for the adolescents' perceived closeness of interpersonal relationships and school well-being fit the data well: $\chi^{2}(1081)=2008.64, p<0.001, \mathrm{CFI}=0.94$, RMSEA $=0.03$, SRMR $=0.05$. After controlling for the stabilities of the constructs, the results illustrated that the cross-lagged paths from closeness to parents $(\beta=0.07, \mathrm{SE}=0.03, p=$ 0.049 ) and to school friends $(\beta=0.10, \mathrm{SE}=0.04, p=$ 0.006 ) in the fall of the sixth grade to school satisfaction in the fall of the seventh grade, and from closeness to parents in the fall of the seventh grade $(\beta=0.11, \mathrm{SE}=0.04, p=$ 0.002) to school satisfaction in the spring of the seventh grade were positive. Furthermore, the cross-lagged paths from closeness to parents in the fall of the sixth grade $(\beta=$ $-0.12, \mathrm{SE}=0.05, p=0.011)$ to school stress in the fall of the seventh grade, and from closeness to parents in the spring of the seventh grade $(\beta=-0.09, \mathrm{SE}=0.04, p=$ $0.021)$ to school stress in the spring of the seventh grade were negative. Finally, cross-lagged paths from school satisfaction in the fall of the sixth grade to the subsequent perceived closeness to parents $(\beta=0.15, \mathrm{SE}=0.03, p<$ $0.001)$, friends $(\beta=0.10, \mathrm{SE}=0.04, p=0.007)$, and teachers $(\beta=0.09, \mathrm{SE}=0.04, p=0.033)$ in the fall of the seventh grade were positive. In addition, a significant indirect effect (estimate $=0.023, \mathrm{SE}=0.010, p=0.024$ ) 


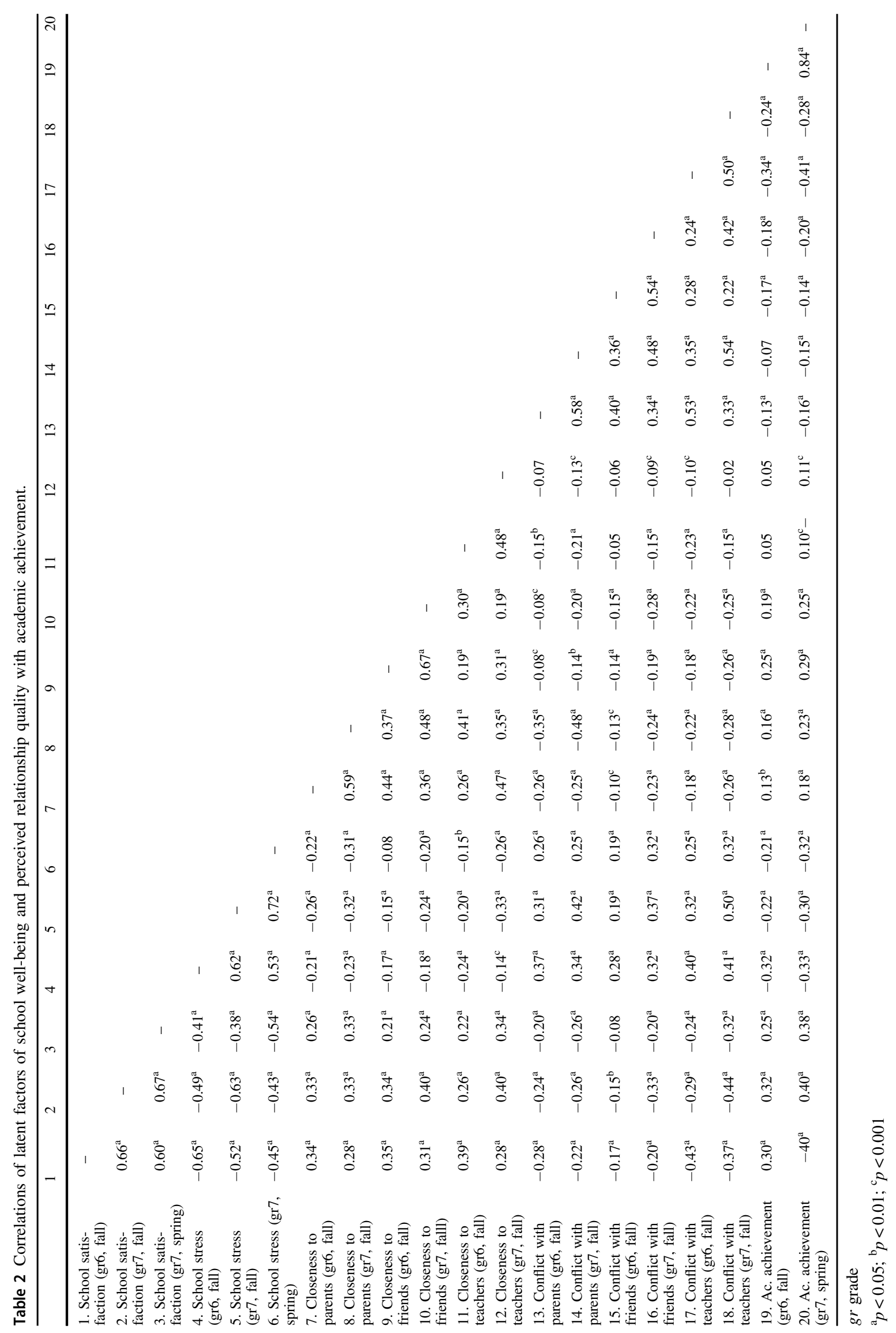


was detected from high school satisfaction in the fall of the sixth grade to increased school satisfaction in the spring of the seventh grade through increased closeness to parents in the fall of the seventh grade. Similarly, an indirect effect (estimate $=-0.014, \mathrm{SE}=0.006, p=0.024)$ from high school satisfaction in the fall of the sixth grade to decreased school stress in the spring of the seventh grade through increased closeness to parents in the fall of the seventh grade was significant.

\section{Conflict in Interpersonal Relationships and School Well-being}

The final model for the adolescents' perceived conflict in interpersonal relationships and school well-being fit the data well: $\chi^{2}(909)=1394.80, p<0.001, \mathrm{CFI}=0.97$, RMSEA $=$ 0.03 , SRMR $=0.05$. The cross-lagged path from conflict with teachers in the fall of the sixth grade to school stress in the fall of the seventh grade $(\beta=0.08, \mathrm{SE}=0.04, p=$ 0.037 ) was positive, whereas the cross-lagged path from conflict with parents in the fall of the seventh grade to school satisfaction in the spring of the seventh grade $(\beta=$ $-0.07, \mathrm{SE}=0.03, p=0.024)$ was negative. Similarly, the cross-lagged paths from school stress in the fall of the sixth grade to the subsequent perceived conflict with parents $(\beta$ $=0.15, \mathrm{SE}=0.04, p<0.001)$, friends $(\beta=0.19, \mathrm{SE}=0.03$, $p<0.001)$ and teachers $(\beta=0.25, \mathrm{SE}=0.04, p<0.001)$ in the fall of the seventh grade were positive. In addition, a significant indirect effect (estimate $=0.019, \mathrm{SE}=0.008, p$ $=0.017$ ) was detected from low school satisfaction in the fall of the sixth grade to decreased school satisfaction in the spring of the seventh grade through increased conflict with parents in the fall of the seventh grade. Similarly, an indirect effect (estimate $=-0.014, \mathrm{SE}=0.007, p=0.047$ ) from high school stress in the fall of the sixth grade to decreased school satisfaction in the spring of the seventh grade through increased conflict with parents in the fall of the seventh grade was significant.

\section{Structural Equation Models for Interpersonal Relationships, School Well-being, and Academic Achievement}

As the final step, the participants' academic achievement was incorporated into the previously estimated models for perceived quality of interpersonal relationships and school well-being.

\section{Models for Closeness}

The final combined SEMs for closeness in interpersonal relationships, school well-being, and academic achievement is shown in Fig. 2. The results for cross-lagged paths between closeness in interpersonal relationships and school well-being were same than those reported in the previous models (see Fig. 2). In addition, two significant cross-lagged effects for academic achievement were found. First, high academic achievement predicted the adolescents' increased school satisfaction in the fall of the seventh grade. Second, high school satisfaction in the fall of the seventh grade predicted the adolescents' increased academic achievement in the spring of the seventh grade. Three statistically significant indirect effects were detected as well (see Table 3): the adolescents' high closeness to their parents and friends in the fall of the sixth grade indirectly promoted the subsequent academic achievement in the spring of the seventh grade through increased school satisfaction in the fall of the seventh grade. In addition, adolescents' high school satisfaction in the fall of the sixth grade indirectly promoted the subsequent academic achievement in the spring of the seventh grade through increased closeness to parents in the fall of the seventh grade.

\section{Models for Conflict}

The final combined SEMs for conflict in interpersonal relationships, school well-being, and academic achievement is shown in Fig. 3. The results for cross-lagged paths between conflict in interpersonal relationships and school well-being were same than those reported in the previous models (see Fig. 3). In addition, four significant cross-lagged effects for academic achievement were found. The first two effects were same than in the model for closeness: high academic achievement predicted the adolescents' increased school satisfaction in the fall of the seventh grade and high school satisfaction in the fall of the seventh grade predicted the adolescents' increased academic achievement in the spring of the seventh grade. In addition, low academic achievement predicted the adolescents' increased conflict with teachers in the fall of the seventh grade. Finally, increased conflict with teachers in the fall of the seventh grade predicted the adolescents decreased academic achievement in the spring of the seventh grade. Also one statistically significant indirect effect was found (see Table 3): school stress in the fall of the sixth grade indirectly hindered subsequent academic achievement in the spring of the seventh grade through increased conflict with teachers immediately after their transition in the fall of the seventh grade.

\section{Additional Analyses}

As additional analyses, the similar analyses reported above were also carried out separately for each type of relationship (school friends, parents, and teachers) without controlling for the effects of other types of relationships. The main pattern for the transactional associations between quality of interpersonal relationships and school well- 


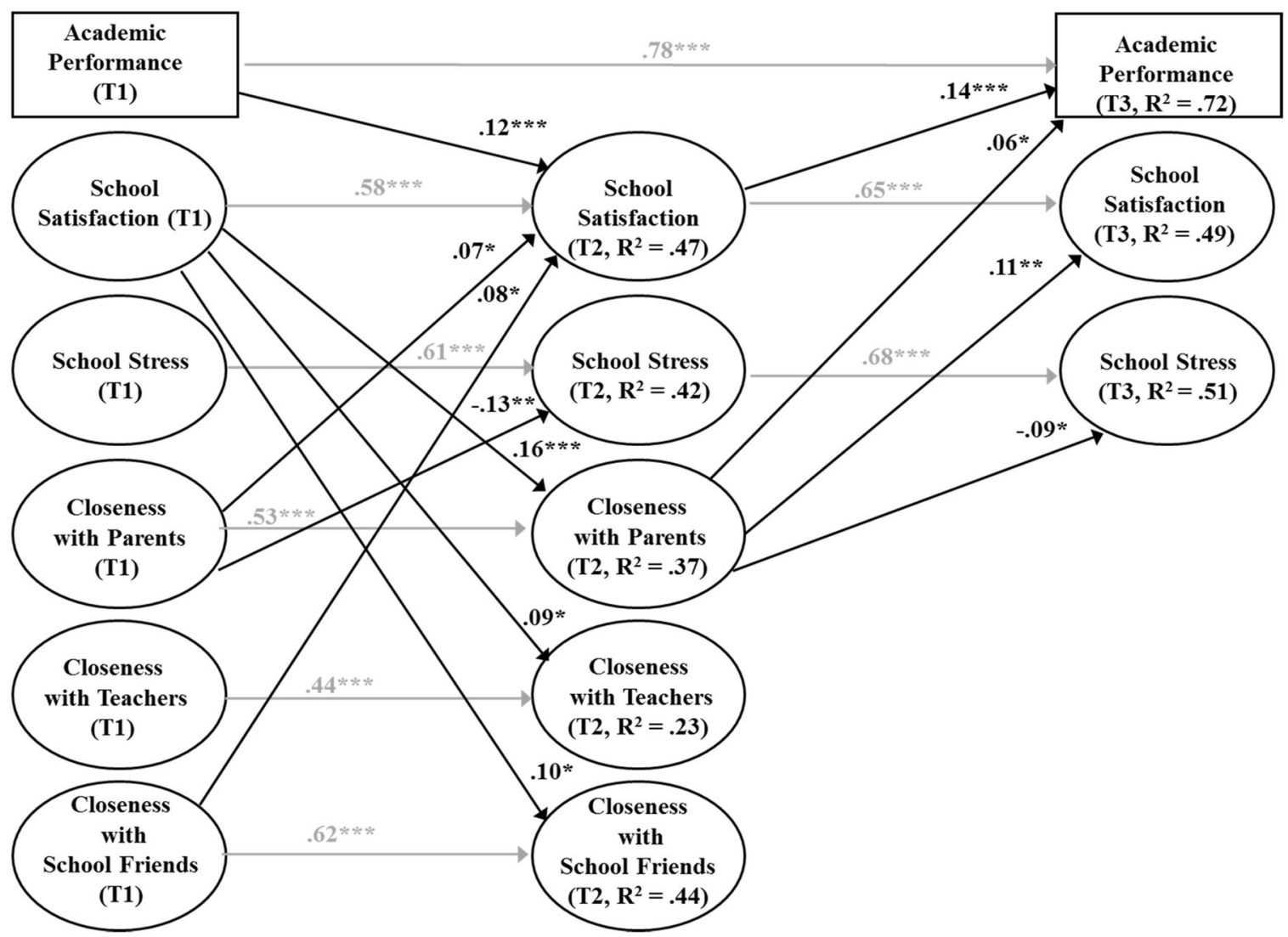

Fig. 2 Final model of closeness of interpersonal relationships, school well-being, and academic achievement. Note. Fit of the model: $\chi^{2}(1169)=2232.82, p<0.001, \mathrm{CFI}=0.95$, $\mathrm{RMSEA}=0.03$, $\mathrm{SRMR}=0.05 . \mathrm{T} 1=$ Grade 6 fall, $\mathrm{T} 2=$ Grade 7 fall, $\mathrm{T} 3=$ Grade

Table 3 Estimates of indirect effects on academic achievement: school well-being in school and quality of interpersonal relationships as mediators $(N=848)$.

\begin{tabular}{lll}
\hline Indirect effect & Estimate & $\mathrm{SE}$ \\
\hline
\end{tabular}

From quality of interpersonal relationships via well-being in school to academic achievement

Closeness to parents $(\mathrm{T} 1) \rightarrow$ School satisfaction $\quad 0.012 * \quad 0.006$

(T2) $\rightarrow$ Academic achievement (T3)

Closeness to school friends $(\mathrm{T} 1) \rightarrow$ School $\quad 0.022 * \quad 0.011$ satisfaction (T2) $\rightarrow$ Academic achievement (T3)

From well-being in school via quality of interpersonal relationships to academic achievement

School satisfaction (T1) $\rightarrow$ Closeness to parents $\quad 0.009 * \quad 0.004$ (T2) $\rightarrow$ Academic achievement (T3)

School stress (T1) $\rightarrow$ Conflict with teachers $\quad-0.027 * * * \quad 0.007$ (T2) $\rightarrow$ Academic achievement (T3)

$* p<0.05 ; * * * p<0.001$

being was similar as reported above. In addition, two additional paths were detected in the models of both relationship closeness and conflict that were not significant when controlling for relationship types with each other.
7 spring. Estimates are shown as standardized estimates. Constructs and residuals of the constructs within the same time points were allowed to correlate. $* p<0.05 ; * * p<0.01 ; * * * p<0.001$.

Furthermore, one additional indirect effect was detected. These differences in the findings are explained in more detail in the following.

\section{Models for Closeness}

A significant cross-lagged effect from high closeness with teachers in the fall of sixth grade to subsequent higher school satisfaction in the fall of seventh grade was detected: ( $\beta=0.08, \mathrm{SE}=0.04, p=0.041)$. In addition, a significant cross-lagged effect from high closeness with friends on subsequent higher academic achievement in the spring of seventh grade was detected $(\beta=0.05, \mathrm{SE}=0.02, p=$ 0.034).

\section{Models for Conflict}

A significant cross-lagged effect from high conflict with parents in the fall of sixth grade and subsequent higher school stress in the fall of seventh grade was detected: $(\beta=$ $0.08, \mathrm{SE}=0.04, p=0.032$ ). Moreover, a significant crosslagged effect from high conflict with parents in the fall of 


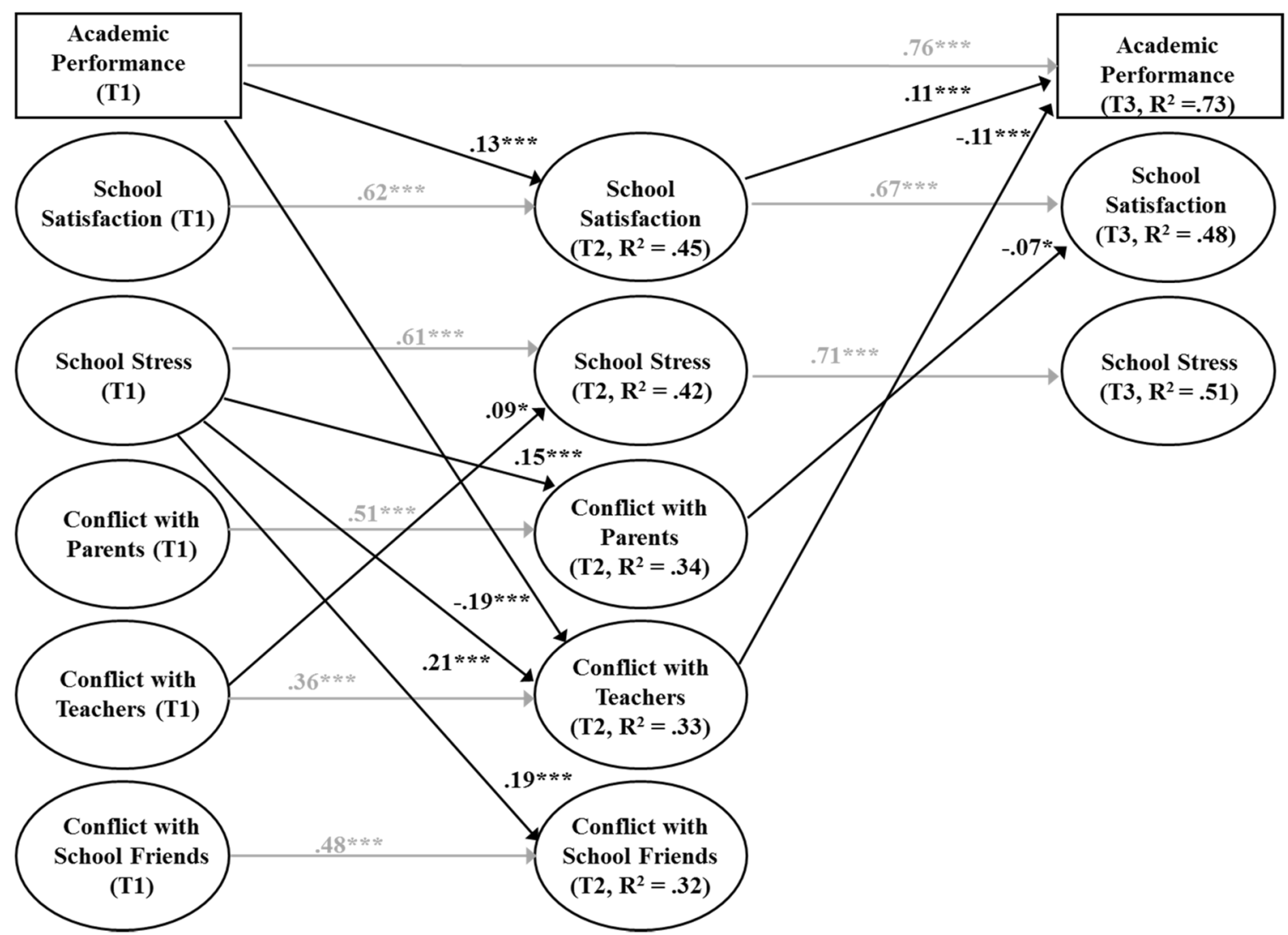

Fig. 3 Final model of conflict in interpersonal relationships, school well-being, and academic achievement. Note. Fit of the model: $\chi^{2}$ $(988)=1561.75, p<0.001, \mathrm{CFI}=0.96, \mathrm{RMSEA}=0.03, \mathrm{SRMR}=$ 0.05. T1 Grade 6 fall, T2 Grade 7 fall, T3 Grade 7 spring. Estimates

seventh grade and subsequent lower academic achievement in the spring of seventh grade was detected: $(\beta=-0.06$, $\mathrm{SE}=0.02, p=0.003)$. In addition, the indirect effect (estimate $=-0.01, \mathrm{SE}=0.004, p=0.008)$ from high stress in the fall of sixth grade on subsequent lower academic achievement in the spring of seventh grade through increased conflict with parents was significant.

\section{Discussion}

Despite the importance of educational transitions for adolescents' academic and well-being outcomes (Wang and Eccles 2012), little is known about the transactional dynamics of interpersonal relationships, school well-being, and academic achievement during the critical transition to lower secondary school. This study examined these dynamics in the school context. The results revealed that closeness to parents and school friends promoted school well-being, while conflict with teachers hindered it. In addition, high levels of school satisfaction promoted relationships with parents, school friends, and teachers, while these relationships were hindered by high levels of school stress. The results also showed that are shown as standardized estimates. Constructs and residuals of the constructs within the same time points were allowed to correlate. ${ }^{*} p<$ $0.05 ; * * p<0.01 ; * * * p<0.001$.

adolescents' high quality interpersonal relationships promoted their higher academic achievement through increased school well-being, whereas adolescents' high school well-being promoted their higher academic achievement through increased quality of interpersonal relationships. The results provide novel understanding about reciprocal dynamics of quality of adolescent interpersonal relationships, school wellbeing and academic achievement during critical educational transition.

\section{Transactional Associations between Interpersonal Relationships and School Well-being during the School Transition}

The results generally supported the authors' hypotheses and the transactional model (Sameroff 2010). However, the pattern of results differed, depending on whether positive (i.e., closeness or school satisfaction) or negative (i.e., conflict or school stress) aspects of interpersonal relationships and school well-being were examined and in which phase of the transition the associations were observed. In essence, the results illustrated that supportive relationships with parents continued to play a remarkable 
role when the adolescents moved from primary to lower secondary school. The expected transactional associations were found between the adolescents' relationships with their parents and school well-being. High perceived closeness to (but not perceived conflict) with parents predicted the adolescents' higher subsequent school wellbeing (in regard to high school satisfaction and low school stress), whereas high school well-being predicted higher quality relationships with parents. The results suggested that support and encouragement from parents are helpful for adolescents when facing the challenging transition from primary to lower secondary school (see also Castro et al. 2015; Duineveld et al. 2017; Pina and Gonzales 2014). The relationships between the adolescents and their parents are not necessarily interrupted at transition to the same extent as that of the relationships with their school friends and teachers. Hence, parental support may be more consistently available during transition than support from changing school friends and teachers (Wang et al. 2013; Virtanen et al. 2019).

The expected transactional associations were also detected between the adolescents' school well-being and relationships with school friends (Sameroff 2009): the adolescents' perceived closeness to (but not conflict with) their school friends positively predicted their subsequent school satisfaction (but not school stress). Similarly, the adolescents' high school well-being predicted a higher level of perceived closeness to and a lower level of conflict with school friends. These results suggest that closeness to school friends acts as a particularly promoting factor for the adolescents' school satisfaction, thus highlighting the importance of peer relationships for the adolescents' school well-being. Moreover, school well-being also strongly impacted adolescents' perceived closeness to and conflict with school friends, possibly via transmission of positive and negative emotions (e.g., Aunola et al. 2015), which play a role in the quality of interactions between adolescents and their school friends.

Furthermore, the expected transactional associations were detected between the school well-being and relationships with teachers (Sameroff 2009). These results revealed that particularly a high level of conflict with teachers predicted the adolescents' increased school stress, while closeness to teachers had no effect. This finding suggests that conflict with teachers is particularly detrimental to school well-being, while closeness does not play such an important role, perhaps because of the adolescents' more distant relationships with teachers (Wang et al. 2013) perhaps partly due to discontinuity of teacherstudent relationships across the transition (Virtanen et al. 2019). In addition, the adolescents' high school wellbeing contributed to increased closeness to and decreased conflict with teachers.

\section{Transactional Associations of Interpersonal Relationships and School Well-being and Subsequent Academic Achievement}

The final aim of this study was to investigate how transactional dynamics between interpersonal relationships and school well-being might predict the adolescents' academic achievement during the critical transition to lower secondary school. In line with the expectations, the results indicated that high closeness to parents before the transition indirectly promoted the adolescents' higher subsequent academic achievement through increased school satisfaction after the transition. One mechanism through which the pretransition social support from parents may affect the students' post-transition adaptation at school involves support continuity between the primary and lower secondary school environments. Social support is typically available from the family across the transition and, therefore, it may have longitudinal effects on promoting school well-being and academic outcomes (see Upadyaya and Salmela-Aro 2013; Wang et al. 2011). Parents may also influence adolescents' positive school attitudes and academic achievement by modeling academically oriented behaviors, socializing an achievement orientation, and representing positive values regarding education (Anderson et al. 2007; Castro et al. 2015).

Congruent with the hypotheses, high closeness to friends before the transition indirectly promoted the adolescents' higher subsequent academic achievement through increased school satisfaction after the transition. When maintained across the transition, close and supportive relationships with friends are a readily available source of continuity in the new school environment, which promotes students' adaptation after the transition (Aikins et al. 2005; Kingery et al. 2011). It has been suggested that support from friends before the transition can act as a protective factor after the transition in at least two ways (Hirsch and Dubois 1992; see also Virtanen et al. 2019). First, adolescents with close and supportive relationships with school friends before the transition are more likely to maintain satisfactory posttransition friend networks, and these networks protect them from exposure to potential threats in a new school environment. Second, adolescents may draw upon their earlier sense of support from school friends, employing it as an emotional bank account when facing transition-related challenges.

A high level of conflict with teachers immediately after the transition was also found to directly undermine the adolescents' subsequent academic achievement after the transition, whereas the adolescents' closeness to their teachers had no unique effects on their subsequent school well-being and academic achievement after the transition. These results are in line with research that suggests that relational stressors are 
stronger risk factors than the absence of relational support mechanisms (Hamre and Pianta 2001; Spilt et al. 2012). One possible explanation for the relatively stronger results for post-transition conflict with teachers compared to the posttransition closeness to teachers is that adolescents may have only briefly known their seventh-grade teachers at the time of post-transition measurement. Due to the different subject teacher system of the seventh-grade environment (i.e., different teachers teaching different academic subjects), it is possible that close and supportive relationships with new teachers had not yet formed at the time of this study's measurement. In contrast, if adolescents had faced major conflicts with their new teachers, these challenges would have been perhaps more visible immediately after the transition and had strong negative effects on the adolescents' post-transition well-being and achievement.

Furthermore, the results supported the hypothesis that adolescents' high school satisfaction would indirectly promote subsequent academic achievement through increased closeness to parents and teachers, whereas high school stress would indirectly hinder their subsequent achievement through increased conflicts with teachers. It is possible that low school well-being preceded more distant and strained relationships with parents and teachers (Kiuru et al. 2015; Pomerantz and Eaton 2001; Silinskas et al. 2015), for example, through the transmission of negative emotions while interacting with parents and teachers and through parents' and teachers' increased concern and their attempts to help and control the child. Thus, low quality relationships with parents and teachers would have further detrimental effects on adolescents' academic achievement.

Finally, the analyses did not fully support one of the hypotheses: school well-being did not predict subsequent academic achievement through perceived quality of relationships with friends. One possible explanation for this lack of association is that school well-being may be partly shared in the peer group through emotional contagion and co-rumination of school-related affects and experiences (Kiuru et al. 2008; Lynch et al. 2013; Wang et al. 2018). It is possible that some of the mediating mechanisms occur at the peer group level. In future studies, it is important to investigate peer group phenomena related to school wellbeing and academic achievement, in addition to perceived closeness and conflict in relationships with school friends.

Overall, the results highlighted several mediating mechanisms that explain how the quality of interpersonal relationships and school well-being work together to predict subsequent achievement during educational transitions. Knowledge of the mechanisms that govern how interpersonal environments promote or hinder academic achievement is crucial for any applied research, involving prevention or intervention efforts for improving students' academic achievement. These findings underscore the view that the promotion of students' interpersonal relationships is an important tool in any interventions, aimed at helping adolescents deal with various academic challenges.

The researched phenomenon was also found to be a twoway street: high school well-being promoted higher quality interpersonal relationships, which in turn supported subsequent academic achievement. High levels of school-related stress had detrimental effects on academic achievement; however, these effects were indirect, instead operating through increased difficulties (i.e., conflicts) in interpersonal relationships. Such an accumulation of negative or positive school experiences during the transition to lower secondary school may have long-term consequences for an adolescent's later school performance. The results suggest a need for theoretical models that allow describing more complex associations than merely focusing on the effects arising from parents', friends', and teachers' relationships on later academic skills. According to the transactional theories (Sameroff 2009) underlying this study, both evocative and socialization effects should be considered. The results of this study suggest that it is important to support both adolescent school well-being and the quality of their interpersonal relationships when attempting to promote learning outcomes and reducing challenges related to educational transitions.

\section{Limitations and Future Directions}

This study also has its limitations. First, the present study investigated only adolescents' subjective well-being at school. In future studies, it would be important to investigate other aspects of school well-being, such as health status, school conditions (e.g., safety), or means for selffulfillment in the school context (Konu and Lintonen 2005). Other important challenges for future studies would be to examine the roles of school experiences and school well-being in adolescents' overall well-being (Markkanen et al. 2019; Salmela-Aro et al. 2009), as well as to examine school experiences at daily level. Also, possible spillover effects between different types of social relationships would be worthwhile to be studied (Kiuru et al. 2015). Second, despite the cross-lagged longitudinal design, where rank-order stabilities were statistically controlled, the analyses were nevertheless correlational, which inhibits confident assertions on causality. Third, although information about the adolescents' academic achievement was retrieved from the school registers, the measurement of school well-being and perceived quality of interpersonal relationships were based on adolescents' self-reports. In future studies, it would be important to use multiple reporters (e.g., parents, friends, and teachers) to triangulate data and investigate relationship quality also from the perspectives of the parents, friends, and teachers. There are some previous findings to suggest that 
perceptions of shared events can widely vary between different respondents (Cheung et al. 2016; Smetana 1995). Fourth, the present study was carried out in a particular cultural and educational environment (i.e., Finland) within a particular historical time. This may limit generalizability of the results to other contexts. It would be worthwhile to replicate the findings in other cultural and educational environments. Fifth, the present study only investigated the mechanisms mediating the effects of the quality of interpersonal relationships and school wellbeing on adolescents' academic achievement. A challenge for future researchers would be to investigate multiple mediators and longer mediator chains, such as investigating possible motivation-related mediators as intervening mechanisms. Finally, the investigation of potential moderators (e.g., adolescent temperament or learning difficulties) among the associations between quality of interpersonal relationships and school well-being in regard to adolescents' academic achievement remains a challenge for future research.

\section{Conclusion}

Educational transitions allow researchers to explore how school well-being and interpersonal relationships relate to academic achievement over time. This study offered a novel insight into the dynamics between school well-being, the quality of interpersonal relationships, and academic achievement during the transition from primary to lower secondary school. Results suggest that adolescents' highquality interpersonal relationships with parents and peers that are characterized by closeness, encouragement, and support serve as developmental assets for negotiating school transitions. In contrast, conflicts with new teachers after the transition appeared to act as a risk factor. Thus, school policies and structures aimed at enhancing a lower secondary school teacher's ability to connect with students in emotionally supportive ways may prevent the accumulation of non-supportive classroom experiences and other potential threats to learning outcomes. Results also highlighted several mediating mechanisms that elucidate how the quality of interpersonal relationships and school well-being work together to predict subsequent academic achievement during educational transitions. These findings underscore the importance of leveraging adolescents' interpersonal relationships as an intervention tool to help them cope with various academic challenges.

Acknowledgements This study forms part of the STAIRWAY-From Primary School to Secondary School Study (Ahonen \& Kiuru, 2013). The study was funded by grants from the Academy of Finland (\#266851, 294970). Open access funding provided by University of Jyväskylä (JYU).
Data Sharing Declaration The datasets generated and/or analyzed during the current study are not publicly available but are available from the corresponding author on reasonable request.

Authors' Contributions NK conceived of the study, participated in the design and coordination, analyzed the data and drafted the manuscript; MW participated in the design and interpretation of the data and helped to draft the manuscript; KS and LK participated in the design and interpretation of the data; TA participated in the design and coordination of the study; $\mathrm{RH}$ participated in the design and coordination of the study and helped to draft the manuscript. All authors read and approved the final manuscript.

\section{Compliance with Ethical Standards}

Conflict of Interest The authors declare that they have no conflict of interest.

Ethical Approval This study was conducted in compliance with APA ethical standards. It was approved by the Ethics Committee of the University of Jyväskylä,

Informed Consent Informed consent was obtained from all the participants of the study.

Publisher's note Springer Nature remains neutral with regard to jurisdictional claims in published maps and institutional affiliations.

Open Access This article is distributed under the terms of the Creative Commons Attribution 4.0 International License (http://crea tivecommons.org/licenses/by/4.0/), which permits unrestricted use, distribution, and reproduction in any medium, provided you give appropriate credit to the original author(s) and the source, provide a link to the Creative Commons license, and indicate if changes were made.

\section{References}

Aikins, J. W., Bierman, K. L., \& Parker, J. G. (2005). Navigating the transition to junior high school: the influence of pre-transition friendship and self-system characteristics. Social Development, 14, 42-60. https://doi.org/10.1111/j.1467-9507.2005.00290.x.

Anderson, S. A., Sabatelli, R. M., \& Kosutic, I. (2007). Families, urban neighborhood youth centers, and peers as contexts for development. Family Relations, 56, 346-357. https://doi.org/10.1111/j.1741.

Asparouhov, T., \& Muthén, B. (2006). Multilevel modeling of complex survey data. Proceedings of the Joint Statistical Meeting (pp. 2718-2726). Seattle, WA: ASA Section on Survey Research Methods.

Aunola, K., Tolvanen, A., Kiuru, N., Kaila, S., Mullola, S., \& Nurmi, J.-E. (2015). A person-oriented approach to diary data: Children's temperamental negative emotionality increases susceptibility to emotion transmission in father-child-dyads. Journal of PersonOriented Research, 1, 72-86.

Baker, J. A., Dilly, L. J., Aupperlee, J. L., \& Patil, S. A. (2003). The development of school satisfaction: schools as psychologically healthy environments. School Psychology Quarterly, 18, 206-221. https://doi.org/10.1521/scpq.18.2.206.21861.

Bond, L., Butler, H., Thomas, L., Carlin, J., Glover, S., \& Bowes, G., et al. (2007). Social and school connectedness in early secondary school as predictors of late teenage substance use, mental health, and academic outcomes. Journal of Adolescent Health, 40, 9-18. 
Browne, M. W., \& Cudeck, R. (1993). Alternative ways of assessing model fit. In K. A. Bollen \& J. S. Long (Eds), Testing structural equation models (pp. 136-162). Beverly Hills, CA: Sage.

Bukowski, W. M., Hoza, B., \& Boivin, M. (1994). Measuring friendship quality during pre- and early adolescence: The development and psychometric properties of the friendship qualities scale. Journal of social and Personal Relationships, 11, 471-484. https://doi.org/10.1177/0265407594113011.

Burchinal, M. R., Roberts, J. E., Zeisel, S. A., \& Rowley, S. J. (2008). Social risk and protective factors for African American children's academic achievement and adjustment during the transition to middle school. Developmental Psychology, 44, 286-292. https:// doi.org/10.1037/0012-1649.44.1.286.

Castro, M., Expósito-Casas, E., López-Martín, E., Lizasoain, L., Navarro-Asencio, E., \& Gaviria, J. L. (2015). Parental involvement on student academic achievement: A meta-analysis. Educational Research Review, 14, 33-46.

Cheung, C. S., Pomerantz, E. M., Wang, M., \& Qu, Y. (2016). Controlling and autonomy-supportive parenting in the United States and China: Beyond Children's reports. Child Development, 87, 1992-2007.

Currie, C., Zanotti, C., Morgan, A., Currie, D., de Looze, M., Roberts, C. \& Barnekow, V. (Eds) (2012). Social determinants of health and well-being among young people. Health Behaviour in School-aged Children (HBSC) study: international report from the 2009/2010 survey. Health Policy for Children and Adolescents, No. 6. Copenhagen: World Health Organization.

Deci, E. L., \& Ryan, R. M. (2000). The "what" and "why" of goal pursuits: Human needs and the self-determination of behavior. Psychological Inquiry, 11, 227-268.

Driscoll, K., \& Pianta, R. (2011). Mothers' and fathers' perceptions of conflict and closeness in parent-child relationships during early childhood. Journal of Early Childhood and Infant Psychology, 7, $1-24$.

Duineveld, J. J., Parker, P. D., Ryan, R. M., Ciarrochi, J., \& SalmelaAro, K. (2017). The link between perceived maternal and paternal autonomy support and adolescent well-being across three major educational transitions. Developmental Psychology, 53, 1978-1994. https://doi.org/10.1037/dev0000364.

Eccles, J. S. (2004). Schools, academic motivation, and stageenvironment fit. In R. M. Lerner \& L. D. Steinberg (Eds), Handbook of adolescent psychology (pp. 125-153). Hoboken, NJ: Wiley.

Eccles, J. S., \& Roeser, R. W. (2011). Schools as developmental contexts during adolescence. Journal of Research on Adolescence, 21, 225-241. https://doi.org/10.1111/j.1532-7795.2010. 00725.x.

Hamm, J. V., \& Zhang, L. (2010). The schooling context of adolescents' peer relations. In J. Meece \& J. Eccles (Eds), The handbook of schools and schooling effects on development (pp. 518-554). Mahwah, NJ: Erlbaum.

Hamre, B. K., \& Pianta, R. C. (2001). Early teacher-child relationships and the trajectory of children's school outcomes through eighth grade. Child Development, 72, 625-638.

Hill, N. E., \& Wang, M.-T. (2015). From middle school to college: developing aspirations, promoting engagement, and indirect pathways from parenting to post high school enrollment. Developmental Psychology, 51, 224-235.

Hirsch, B. J., \& Dubois, D. L. (1992). The relation of peer social support and psychological symptomatology during the transition to junior high school: A two-year longitudinal analysis. American Journal of Community Psychology, 20, 333-347. https://doi.org/ 10.1007/BF00937913.

Hoyle, R. H. (1995). The structural equation modeling approach: Basic concepts and fundamental issues. In R. H. Hoyle (ed.), Structural equation modeling: Concepts, issues, and applications (p. 1-15). Sage Publications, Inc.

Hu, L.-T., \& Bentler, P. M. (1999). Cut-off criteria for fit indexes in covariance structure analysis. Conventional criteria versus new alternatives. Structural Equation Modeling, 6, 1-55.

Huebner, E. S., \& Gilman, R. (2006). Students who like and dislike school. Applied Research in quality of life, 1, 139-150. https:// doi.org/10.1007/s11482-006-9001-3.

Jerome, E. M., Hamre, B. K., \& Pianta, R. C. (2008). Teacher-child relationships from kindergarten to sixth grade: Early childhood predictors of teacher-perceived conflict and closeness. Social Development, 18, 915-945. https://doi.org/10.1111/j.1467-9507. 2008.00508.x.

Kerr, M., \& Stattin, H. (2003). Parenting of adolescents: action or reaction? In A. C. Crouter, A. Booth, (Eds). Children's influence on family dynamics: the neglected side of family relationships. (pp. 121-152). Mahwah: New Jersey: Lawrence Erlbaum.

Kindermann, T. A. (2016). Peer group influences on students' academic motivation. In: TeoksessaK. R. Wentzel, G. B. (Eds). Handbook of social influences in school contexts. (pp. s.31-47). New York, NY: Routledge.

Kingery, J. N., Erdley, C. A., \& Marshall, K. C. (2011). Peer acceptance and friendship as predictors of early adolescents' adjustment across the middle school transition. Merrill-Palmer Quarterly, 57, 215-243. https://doi.org/10.1353/mpq.2011.0012.

Kiuru, N., Aunola, K., Lerkkanen, M.-K., Pakarinen, E., Poskiparta, E., Ahonen, T., Poikkeus, A.-M., \& Nurmi, J.-E. (2015). Positive teacher and peer relations combine to predict primary school students' academic skill development. Developmental Psychology, 51, 434-446.

Kiuru, N., Aunola, K., Nurmi, J.-E., Leskinen, E., \& Salmela-Aro, K. (2008). Peer group influence and selection in adolescents' school burnout: a longitudinal study. Merrill-Palmer Quarterly, 54, 23-55.

Kiuru, N., Pakarinen, E., Vasalampi, K., Silinskas, G., Aunola, K., \& Poikkeus, A.-M., et al. (2014). Task-focused behavior mediates the associations between supportive interpersonal environments and students' academic performance. Psychological Science, 25, $1018-1024$.

Konu, A., \& Lintonen, T. (2005). Theory-based survey analysis of well-being in secondary schools in Finland. Health Promotion International, 21, 27-36. https://doi.org/10.1093/heapro/dai028.

Kämppi, K., Välimaa R., Ojala, K., Tynjälä, J. Haapasalo, I., Villberg, J., \& Kannas, L. (2012). Koulukokemusten kansainvälistä vertailua 2010 sekä muutokset Suomessa ja Pohjoismaissa 19942010 - WHO-koululaistutkimus (HBSC Study) [International comparison of school experiences in 2010 and changes in Finland and in the Nordic countries from 1994 to 2010 - The Health Behavior of School-aged Children study]. Helsinki: Finnish National Board of Education, report on monitoring education 2012:8.

Longobardi, C., Pino, L. E., Marengo, D., \& Settanni, M. (2016). Student-teacher relationships as a protective factor for school adjustment during the transition from middle to high school. Frontiers in Psychology, 7. https://doi.org/10.3389/fpsyg.2016. 01988.

Lynch, A. D., Lerner, R. M., \& Leventhal, T. (2013). Adolescent academic achievement and school engagement: An examination of the role of school-wide peer culture. Journal of Youth and Adolescence, 42, 6-19. https://doi.org/10.1007/s10964-0129833-0.

MacKinnon, D. P., Lockwood, C. M., \& Williams, J. (2004). Confidence limits for the indirect effect: distribution of the product and resampling methods. Multivariate Behavioral Research, 39, 99-128. https://doi.org/10.1207/s15327906mbr3901_4.

Markkanen, I., Välimaa, R., \& Kannas, L. (2019). Associations between students' perceptions of the psychosocial school 
environment and indicators of subjective health in Finnish comprehensive schools. Children \& Society, 33, 488-502. https://doi. org/10.1111/chso. 12334 .

Mauno, S., Hirvonen, R., \& Kiuru, N. (2018). Children's life satisfaction: The roles of mothers' work engagement and recovery from work. Journal of Happiness Studies, 19, 1379-1393. https:// doi.org/10.1007/s10902-017-9878-6.

Moore, G.F., Cox, R., Evans, R.E., Hallingberg, B., Hawkings, J., Littlecott, H.J., et al. (2018). School, peer and family relationships and Aadolescent substance use, subjective wellbeing and mental health symptoms in Wales: a cross sectional study. Child Indicators Research, 11, 1951-1965.

Muthén, L., \& Muthén, B. O. (1998-2018). Mplus Version 8 \& Mplus users' guide, Los Angeles, CA: Muthén and Muthén. http://www. statmodel.com.

Muthén, B., \& Satorra, A. (1995). Complex sample data in structural equation modeling. Sociological Methodology, 25, 267-316. https://doi.org/10.2307/271070.

Nurmi, J.-E., \& Kiuru, N. (2015). Students' evocative impact on teacher instruction and teacher-child relationships: Theoretical background and an overview of previous research. International Journal of Behavioral Development, 39, 445-457. https://doi.org/ $10.1177 / 0165025415592514$.

Official Statistics of Finland. (2016a). Educational structure of population (e-publication). Helsinki, Finland: Statistics Finland. www.stat.fi/til/ vkour/2014/vkour_2014_2015-11-05_tie_001_en.html.

Official Statistics of Finland. (2016b). Families. Appendix Table 3: families with underage children by type in 1950-2014 (e-publication). Helsinki, Finland: Statistics Finland. www.stat.fi/til/ perh/2014/perh_2014_2015-05-28_tau_003_en.html.

Ottová-Jordan, V., Smith, O. R. F., Augustine, L., Gobina, I., Rathmann, K., \& Torsheim, T., et al. (2015). Trends in health complaints from 2002 to 2010 in 34 countries and their association with health behaviours and social context factors at individual and macro-level. European Journal of Public Health, 25(Supplement 2), 83-89. https://doi.org/10.1093/eurpub/ckv033.

Park, S., Holloway, S. D., Arendtsz, A., Bempechat, J., \& Li, J. (2012). What makes students engaged in learning? A time-use study of within- and between-individual predictors of emotional engagement in low-performing high schools. Journal of Youth and Adolescence, 41, 390-401.

Pianta, R. C. (2001). The student-teacher relationship scale. Odessa, FL: Personality Assessment Research.

Pina, A. A., \& Gonzales, N. A. (2014). The role of theory and culture in child and adolescent prevention science. Journal of Clinical Child \& Adolescent Psychology, 43, 397-399.

Pyhältö, K., Soini, T., \& Pietarinen, J. (2010). Pupils' pedagogical well-being in comprehensive school-significant positive and negative school experiences of Finnish ninth graders. European Journal of Psychology of Education, 25, 207-221. https://doi.org/ 10.1007/s10212-010-0013-x

Pomerantz, E. M., \& Eaton, M. M. (2001). Maternal intrusive support in the academic context: transactional socialization processes. Developmental Psychology, 37, 174-186.

Quin, D. (2017). Longitudinal and contextual associations between teacher-student relationships and student engagement: A systematic review. Review of Educational Research, 87, 345-387.

Ryan, R. M., \& Deci, E. L. (2017). Self-determination theory: basic psychological needs in motivation, development, and wellness. New York, NY: Guilford Press Publishing.

Salmela-Aro, K., Kiuru, N., Leskinen, E., \& Nurmi, J.-E. (2009). School-burnout inventory (SBI) - reliability and Validity. European Journal of Psychological Assessment, 25, 48-57.

Salmela-Aro, K., \& Upadyaya, K. (2014). School burnout and engagement in the context of demands-resources model. British Journal of Educational Psychology, 84, 137-151.
Samdal, O. (2017). School Health Promotion. In: S. R. Quah \& W. C. Cockerham (Eds). The international encyclopedia of public health. 2nd edition. vol. 6. Oxford: Academic Press.

Samdal, O., Dür, W., \& Freeman, J. (2004). School. In C. Currie, C. Roberts, A. Morgan, R. Smith, W. Settertobulte \& O. Samdal et al. (Eds), Young people's health in context: international report from the HBSC 2001/02 survey. Health policy for children and adolescents (pp. 42-52). Copenhagen: World Health Organization.

Sameroff, A. (2009). The transactional model of development: How children and contexts shape each other. Washington, DC: American Psychological Association.

Sameroff, A. (2010). A unified theory of development: a dialectic integration of nature and nurture. Child Development, 81, 6-22. https://doi.org/10.1111/j.1467-8624.2009.01378.x.

Silinskas, G., Kiuru, N., Aunola, K., Lerkkanen, M.-K., \& Nurmi, J.E. (2015). The developmental dynamics of children's academic performance and mothers' homework-related affect and practices. Developmental Psychology, 51, 419-433. https://doi.org/10. 1037/a0038908.

Smetana, J. D. (1995). Parenting styles and conceptions of parental authority during adolescence. Child Development, 66, 299-316.

Sonmark, K., \& Modin, B. (2017). Psychosocial work environment in school and students' somatic health complaints: an analysis of buffering resources. Scandinavian Journal of Public Health, 45, 64-72. https://doi.org/10.1177/1403494816677116.

Spilt, J. L., Hughes, J. N., Wu, J.-Y., \& Kwok, I.-M. (2012). Dynamics of teacher-student relationships: Stability and change across elementary school and the influence on children's academic success. Child Development, 83, 1180-1195. https://doi.org/10.1111/j. 1467-8624.2012.01761.x.

Steinberg, L., \& Morris, A. S. (2001). Adolescent development. Annual Review of Psychology, 52, 83-110.

Upadyaya, K., \& Salmela-Aro, K. (2013). Development of school engagement in association with academic success and well-being in varying social contexts: a review of empirical research. European Psychologist, 18, 136-147. https://doi.org/10.1027/10169040/a000143.

Verschueren, K. (2015). Middle childhood teacher-child relationships: Insights from an attachment perspective and remaining challenges. In G. Bosmans \& K. A. Kerns (Eds), Attachment in middle childhood: theoretical advances and new directions in an emerging field. New Directions for Child and Adolescent Development 148, (77-91).

Virtanen, T. E., Vasalampi, K., Kiuru, N., Lerkkanen, M.-K., \& Poikkeus, A.-M. (2019). The role of perceived social support as a contributor to the successful transition from primary to lower secondary school. Scandinavian Journal of Educational Research. https://doi.org/10.1080/00313831.2019.1639816.

Wang, M.-T., \& Brinkworth, M., \& Eccles, J. (2013). Moderating effects of teacher-student relationship in adolescent trajectories of emotional and behavioral adjustment. Developmental Psychology, 49, 690-705.

Wang, M.-T., Degol, J. L., \& Henry, D. A. (2019). An integrative development-in-sociocultural-context model for children's engagement in learning. American Psychologist, 74, 1086-1102.

Wang, M.-T., \& Eccles, J. S. (2012). Social support matters: Longitudinal effects of social support on three dimensions of school engagement from middle to high school. Child Development, 83, 877-895. https://doi.org/10.1111/j.1467-8624.2012.01745.x.

Wang, M.-T., Dishion, T. J., Stormshak, E. A., \& Willett, J. (2011). Trajectories of family management practices and early adolescent behavioral outcomes. Developmental Psychology, 47, 1324-1341.

Wang, M.-T., Kiuru, N., Degol, J., \& Salmela-Aro., K. (2018). Friends, academic achievement, and school engagement during adolescence: A social network approach to peer influence and 
selection effects. Learning and Instruction, 58, 148-160. https:// doi.org/10.1016/j.learninstruc.2018.06.003.

Waters, S., Lester, L., \& Cross, D. (2014). How does support from peers compare with support from adults as students transition to secondary school? Journal of Adolescent Health, 54, 543-549.

Wentzel, K. (1998). Social relationships and motivation in middle school: the role of parents, teachers, and peers. Journal of Educational Psychology, 90, 202-209.

West, P., Sweeting, H., \& Young, R. (2010). Transition matters: pupils experiences of the primary-secondary school transition in the West of Scotland and consequences for well-being and attainment. Research Papers in Education, 25, 21-50. https://doi.org/ 10.1080/02671520802308677.

Zimmer-Gembeck, M. J., Chipuer, H. M., Hanisch, M., Creed, P. A., \& McGregor, L. (2006). Relationships at school and stageenvironment fit as resources for adolescent engagement and achievement. Journal of Adolescence, 29, 911-933. https://doi. org/10.1016/j.adolescence.2006.04.008.

Noona Kiuru Department of Psychology, University of Jyvaskyla, Finland. Noona Kiuru is an Associate Professor at the University of Jyväskylä. She is interested in youth development, well-being, and social relationships, large-scale interventions, and longitudinal studies.

Ming-Te Wang University of Pittsburg, USA. Ming-Te Wang is a Professor of Psychology and Education at the University of Pittsburgh. He received his doctorate in Human Development and Psychology from Harvard University. His major research interests include achievement motivation and engagement, school climate and parental socialization, diversity, opportunity, and equity, stereotype threat and learning, and psychosocial intervention.

Katariina Salmela-Aro Department of Educational Sciences, University of Helsinki, Finland. Katariina Salmela-Aro is a Professor at the University of Helsinki. Her research interests include student engagement and burnout, longitudinal and situational approaches and related interventions.

Lasse Kannas Faculty of Sport and Health Sciences, University of Jyväskylä, Finland. Lasse Kannas is an Emeritus Professor at the University of Jyväskylä. His research interests include students' wellbeing, school perceptions, health behaviors and school health promotion.

Timo Ahonen Department of Psychology, University of Jyvaskyla, Finland. Timo Ahonen is an Emeritus Professor at the University of Jyväskylä. He is interested in learning and learning disabilities, clinical child neuropsychology, and developmental psychology.

Riikka Hirvonen School of Applied Educational Science and Teacher Education, University of Eastern Finland, Finland. Riikka Hirvonen is a Senior Researcher at the University of Eastern Finland. Her research interests include students' well-being, motivation, and learning-related emotions and behavior. 